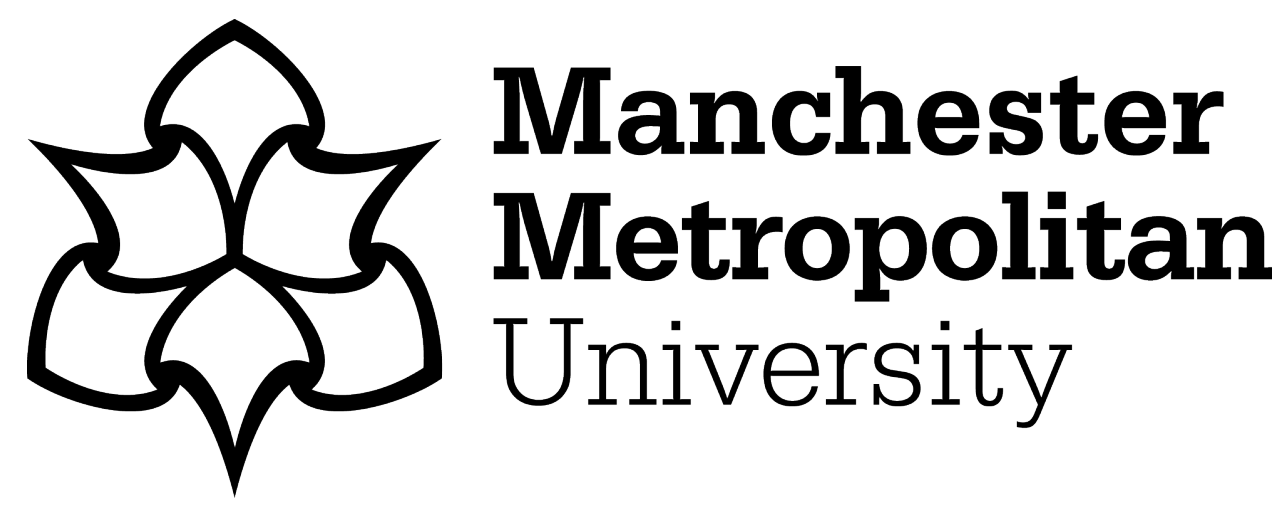

Turner, Nicola, Schneider, Justine, Pollock, Kristian, Travers, Cheryl, PerryYoung, Lucy and Wilkinson, Samantha (2020) 'Going the extra mile' for older people with dementia: exploring the voluntary labour of homecare workers. Dementia, 19 (7). pp. 2220-2233. ISSN 1471-3012

Downloaded from: https://e-space.mmu.ac.uk/622087/

Publisher: SAGE Publications

DOI: https://doi.org/10.1177/1471301218817616

Please cite the published version 


\title{
'Going the extra mile for older people with dementia: exploring the voluntary labour of homecare workers
}

\begin{abstract}
Homecare workers provide essential physical, social and emotional support to growing numbers of older people with dementia in the UK. Although it is acknowledged that the work can sometimes be demanding, some homecare workers regularly 'go the extra mile' for service users, working above and beyond the usual remit of the job. This form of voluntarism has been interpreted as an expression of an essentially caring nature, but also as the product of a work environment structured to tacitly endorse the provision of unpaid labour. This paper draws on a qualitative study of what constitutes 'good' homecare for older people with dementia. Using homecare workers' reflexive diaries $(n=11)$ and interviews with homecare workers $(n=14)$ and managers $(n=6)$, we explore manifestations of, and motivations for, homecare workers going the extra mile in their everyday work. We describe three modes of voluntary labour based on these accounts which we characterise as affective, performative and pragmatic. Our study highlights the complex relationships between job satisfaction, social benefit and commercial gain in the homecare work sector. Further research is needed to define the full range of affective and technical skills necessary to deliver good homecare, and to ensure that homecare work is appropriately credited.
\end{abstract}

Keywords: home care, care work, older people, unpaid labour, job satisfaction 


\section{INTRODUCTION}

Homecare workers provide essential services to people living at home who require additional support to maintain well-being, foster social engagement and participate in their local community. This includes growing numbers of older people, many of whom have multiple and complex needs. According to the Alzheimer's Society, 60 per cent of homecare service users in the UK have some form of dementia (Carter, 2016). With the number of people living with dementia expected to rise from 800,000 to over one million by 2025 (Alzheimer's Society, 2014), ensuring the supply of high quality home care is a matter of increasing concern for policy-makers, commissioners, providers and consumers.

Research has drawn attention to the problem of recruiting and retaining staff in the homecare sector (Humphries, Thorlby, Holder, Hall \& Charles, 2016). A report by the UK Home Care Association (UKHCA) found that between 2015 and 2016, the rate of staff turnover increased from 32 per cent to 41 per cent (Holmes, 2016). Low pay, lack of training, irregular hours and the low status of care work have been cited as reasons for homecare workers' dissatisfaction with the job (Banijamali, Jacoby \& Hagopian, 2014; Fleming \& Taylor, 2007; Jang et al. 2015). Yet some homecare workers love their work (Sims-Gould, Byrne, Craven, Martin-Matthews \& Keefe, 2010); therefore, one response to the burgeoning recruitment crisis in homecare has been to seek out those whose personal values may predispose them towards caring for others regardless of material rewards.

The move towards values-based recruitment in homecare focusses attention on the affective capabilities of potential homecare workers in addition to their practical skills 
(Skills for Care, 2016). Affective capabilities include the ability to assess service users' feelings, to facilitate a positive emotional environment and to elicit desired emotional responses in the course of their work. The reprioritisation of the affective dimension of homecare work can be seen in part as a corrective response to inquiries into failings in residential and nursing care, where the qualities of compassion, empathy and respect for service users were found to be sorely lacking (Bubb, 2014; Francis, 2013). The affective capabilities of homecare workers are also known to be highly valued by service users (de São José, Barros, Samitca \& Teixeira, 2016; Manthorpe, Harris, Samsi \& Moriarty, 2017).

The growing recognition of the value of homecare workers' affective skills and resources raises questions concerning what level of emotional investment in the job may be regarded as appropriate, and whether there is a risk of homecare workers' emotions being exploited in the course of their work (Ward \& McMurray, 2016). Doing a good job in homecare has often been associated with a willingness to go beyond the role requirements, or 'going the extra mile' (Johnson, 2015; Stacey, 2005). Going the extra mile refers to homecare workers providing care above and beyond the duties set out in their terms of employment; therefore by definition, giving care for which they are not paid. This form of voluntarism concerns more than physical labour, such as working beyond their contracted time to complete tasks. Even during paid working hours, homecare workers may be delivering affective support that is not part of their usual job description.

In preparation for our in-depth study, we reviewed 17 homecare worker job descriptions located online and studied in depth eight of these selected at random. These focussed on 
practical elements of the role: seven of the eight mentioned assisting with personal care, internal liaison, record keeping and housekeeping duties. Only three referred to providing companionship or sharing activities and interests with service users, while two mentioned helping service users to participate in their local community. Affective labour may be implied by the activities specified, but it did not appear in job descriptions. For example, giving reassurance, persuading and empathising are affective skills that support successful communication between individuals. Insofar as homecare workers utilise such skills they go beyond the typical job description for the role.

In this paper, we explore the experience of going the extra mile from the on-the-job perspectives of homecare workers themselves. The paper draws on a study in which the aim was to inform homecare policy and service development by addressing the question: What does 'good' homecare for older people with dementia look like? The Broadening Our Understanding of Good Homecare (BOUGH) study set out to describe good homecare from the multiple perspectives of service users, family members, homecare workers and local authority commissioners. Here, we focus on the subjective accounts of homecare workers and their managers to examine how the practice of going the extra mile contributes to understandings of what constitutes good homecare, and who makes a good homecare worker. To guide our enquiry we consider two approaches to interpreting homecare workers' motivations for going beyond their role requirements; Stacey's (2011) notion of the 'caring self' focuses on the intrinsic rewards to be gained from care work, whilst Bolton and Wibberley's (2014) application of Labour Process Theory is more concerned with the occupational and organisational contexts in which homecare workers offer their labour to those who use their services. 


\section{The Caring Self}

Stacey (2011) drew on Hochschild's (1983) notion of emotional labour in her study of home health aides in the USA. Emotional labour refers to an employee's purposeful regulation of emotion in accordance with an organisational imperative to maximise profit. The employer's 'feeling rules' guide the appropriate display of on-the-job emotion; for example, homecare workers may be expected to always remain cheerful in the presence of service users (Cranford \& Miller, 2013). Emotional labour may also be used to mask any disgust homecare workers may feel at doing the 'dirty work' of dealing with bodily excretions (Stacey, 2005).

Stacey argued that the location of homecare in private, domestic spaces served to distort occupational feeling rules by blurring the boundary between paid-for care and care provided by family and friends. Within the close confines of the home, many homecare workers reported developing strong, emotional ties with service users similar to kinship bonds. Homecare workers invested substantially in building these relationships and reported high levels of satisfaction with their work.

Stacey's interpretation of homecare workers' emotional labour draws attention to the importance of relationship-building in service sector industries, where the completion of core tasks is facilitated by the presence of a positive relationship between provider and consumer. Whilst Hochschild was concerned with how partitioning and exploiting the emotions of service workers benefits employers (Bailey, Scales, Lloyd, Schneider \& Jones, 2015), Stacey saw the rewards of emotional labour as accruing to homecare workers themselves in the form of increased self-esteem and greater job satisfaction. 
However, the assumption that the rewards of homecare are largely intrinsic can appear to undermine attempts to improve the pay and conditions of the homecare workforce (Palmer \& Eveline, 2012). Moreover, there is a risk that an analysis of emotional labour in occupations dominated by women contributes to an essentialist notion of affective capabilities as inherently female attributes, and of emotional work as women's work. According to this framework, care-giving becomes a vocation for women and a repository for their 'natural' caring abilities, rather than a profession based on formal learning and acquired skills that have value in the labour market (Manthorpe et al., 2017). Briar, Liddell and Tolich (2014) argue that this gendered interpretation of homecare work has had the effect of de-valuing the job and reinforcing the low status and low pay of homecare workers.

\section{Labour Process Theory}

An alternative approach to understanding the emotional investment of homecare workers has been put forward by Bolton and Wibberley (2014), who draw on Labour Process Theory (Thompson \& Smith, 2009) to scrutinise homecare in the broader political and economic context in which it is situated. Labour Process Theory (LPT) highlights the distinction between formal and informal labour within the political economy of homecare. The formal labour process is constituted by control mechanisms that specify tasks a homecare worker is required to undertake; usually in the form of a care plan (or job description). The informal labour process incorporates activities carried out by homecare workers that are not prescribed. These activities may be shaped and determined by the expectations of key stakeholders, including employers, service users, relatives and homecare workers themselves. 
Bolton and Wibberley argue that the increased rationalisation of paid labour has transformed homecare into 'a tightly-defined, task based commodity' (2014: 684) where there is often insufficient time to do the job. The emotional work of relationship-building is squeezed out to become part of the informal labour process undertaken in the homecare worker's own time. Due to the autonomous nature of the role, which is usually carried out in isolation, it is often left for homecare workers to decide how to balance the demands of the job. Thus, whilst Stacey (2011) saw homecare workers' autonomy as empowering, enabling them to engage in emotional labour on their own terms, under Labour Process Theory, the exclusion of emotional work from the formal care process only leaves homecare workers the 'autonomy' to decide whether or not to meet a perceived moral obligation to demonstrate an affective connection with a client.

Having considered these approaches to understanding homecare workers' emotional investment in building the relationships that facilitate their everyday work, we turn now to our study of what constitutes good homecare for older people with dementia. We attend in particular to instances where homecare workers go the extra mile for service users in order to explore how the motivations and rewards for working above and beyond their contractual duties can best be understood.

\section{METHODS}

The BOUGH research was an ethnographic case study of one homecare service provider in England assessed by the Care Quality Commission (CQC) as providing high quality care. The protocol received ethical approval from the UK Health Research Authority Social Care Research Ethics Committee (Reference 15/IEC08/0043). 
Primary data were collected from five sources (Table 1). This approach enabled crosscomparison of findings to develop and consolidate impressions gained.

Table 1: Sources of data for the BOUGH study

1. Participant observation by two researchers who worked as home carers for seven service users with dementia for 11 months

2. Individual interviews with 14 homecare workers and 6 managers

3. Individual interviews with 14 relatives of current and past homecare service users

4. Diaries kept by 11 homecare workers over 16 weeks

5. An online survey and telephone interviews with homecare commissioners from 18 local authorities in England

This paper draws on two data sources to describe homecare workers' subjective experiences of their work role; the interviews with homecare workers and their managers, and the diaries in which they recorded their reflections on homecare work. Other methods of data collection yielded insights into the embodied, sensory experience of performing homecare work, and on the views of relatives and service commissioners. These perspectives will be addressed in future publications.

\section{Homecare worker interviews}

We invited homecare workers to participate in the study via their employing organisation. The provider was supplied with email and paper invitations to distribute to homecare workers. In practice, this enabled homecare workers to be pre-screened, potentially introducing bias in favour of those who might offer a more positive perspective. 
However, it also helped to ensure that study participants had experience of supporting people with dementia.

Fourteen homecare workers and six homecare service managers were recruited.

Homecare workers were offered an inconvenience allowance, and the company were compensated for the time managers spent on the study. Two senior members of the research team carried out individual, semi structured interviews to explore everyday experiences of providing care to people with dementia, how participants came to be involved in homecare work, how they felt about their employment terms and conditions, and their opinions on what makes a good homecare worker. Interviews were recorded and transcribed.

\section{Diaries}

As with the interviews, we invited homecare workers to participate via their employer. Interested homecare workers took part in a group training session on reflexive diarykeeping using specially-designed diaries. Homecare workers were paid at their usual rate for attending the training. Those who agreed to write diaries were paid at their usual rate for up to 16 hours of diary-keeping (two hours per week over eight weeks). One homecare worker opted to use a voice recorder to record her diary and one typed and emailed hers. Handwritten diaries were collected by the researchers to protect confidentiality in relation to other company staff, and the contents were transcribed. The 11 diaries contained a total of 231 entries, with a mean average length of 380 words per diary entry. Two of the diarists also took part in the homecare worker interviews.

\section{Analysis}


The research team read all of the transcripts and met on two occasions to discuss and elaborate a preliminary coding framework guided by the study questions. Constant comparison was applied to identify the occurrence of recurring patterns or 'themes' (Charmaz, 2006). The qualitative software programme NVivo 11 was used to systematically code the interview and diary transcripts, adding to the themes as new concepts emerged. The research team met on two further occasions to relate the emerging themes to core, over-arching analytical categories and explanatory models.

In the following section we report on the results of the analysis, supported by quotations from participants using the abbreviations HW (homecare worker interviewee), HM (homecare manager interviewee) and D (homecare worker diarist).

\section{FINDINGS}

One of the themes to emerge from our analysis was that of homecare workers' accounts of 'going the extra mile' in the service of older people with dementia. In their interviews and diary entries, homecare workers offered numerous examples of using their own resources in the form of time, money, goods, cognitive skills and affective capabilities to perform tasks which went above and beyond their everyday work. We found that homecare workers often described employing considerable empathy and ingenuity to meet the emotional - as well as the physical - needs of service users in challenging situations. In the remainder of this paper, we discuss what prompted homecare workers to go the extra mile, and how their voluntary labour related to individual and organisational understandings of what constitutes good homecare. 
We identified three modes of going the extra mile in homecare workers' accounts. Each mode can be associated with a different set of motivations and rewards for undertaking work that can be perceived as going beyond the usual remit of the job. We have characterised these variations on the theme of voluntary labour as 'affective', 'performative' and 'pragmatic' voluntary labour.

\section{Affective voluntary labour}

Some homecare workers described being intrinsically caring as an important part of their identity. Going the extra mile was an expression of a natural proclivity to be a good carer:

My vicar, the other day when I said I've just got my Caregivers' Certificate, she says, 'You always go the extra mile for anybody in church', she said, 'and I think whoever gets you visiting them, they're really, really lucky, because they know that you'll give the hour you've got there, plus whatever you're over, and if they want errands running, knowing you, you will do it'. And I would.

I get paid for the hours I do, and if I'm giving more than what I am doing, then, I think it just proves that I'm the right sort of person that should be doing the job.

In these examples, voluntary labour is presented as an enactment of the homecare worker's identity, which is characterised by kindness, compassion and empathy for service users. Buying gifts or otherwise incurring costs they met from their own purse appeared to exemplify homecare workers' sense of being a good carer: 
This week, I'm going to make time to go and see one of my clients, because she's not down on my schedule, so I'll make time to go and see her and take her a Christmas present. I like to take food for people. I often turn up with bunches of flowers for people, and just little things that I think, hopefully make a big difference to people's lives.

The act of building and maintaining positive relationships drew on homecare workers' existing relational identities as daughters, grand-daughters and friends, and did not necessarily cease at the end of a shift. Instead, the emotional dimension of their work was often extended in the form of keeping a service user in mind; effectively caring 'outside hours'. Sometimes, homecare workers continued to worry about a service user after they had left:

I was so concerned driving home though. All I could think of was what if [service user] became upset at the [oven timer] alarm? What if she went for a walk and left her lunch in there? What if it caught fire or just smoked out the house? After being at home for only ten minutes I'd become very anxious myself about her safety and rung [service user's son] to tell him how concerned I was.

Some homecare workers reported having formed very strong attachments with service users, and of suffering feelings of loss when the care relationship came to an end:

Feeling quite sad today - not heard from the family of my client who passed away. I would have liked to attend her funeral or send flowers as she loved them, but I have to respect her family's wishes. I have bought some 
daffodils for home to remember her by. I do feel downhearted. I really did go the extra mile for this client.

The emotional investment of homecare workers in building the relationships that delivered good homecare could have a detrimental effect on their sense of well-being as well as representing an unpaid contribution to the care economy. However, it was more often reported as a primary source of job satisfaction:

I love it, I love being able to be with people, and helping people. And just, you know - I'm working all of Christmas. I never mind. I mean, I've always worked Christmas anyway from being in the pub, but this - I love it.

(HW13)

One interpretation of homecare workers' actions in going the extra mile, therefore, suggests that for some, their voluntary labour is intrinsically motivated by an affective disposition towards building relationships with service users and, when it is effective in achieving positive engagement, such as when their kindness is acknowledged or reciprocated, it brings rewards in the form of increased job satisfaction.

\section{Performative voluntary labour}

Descriptions of going the extra mile in homecare workers' accounts often suggested that their additional labour was offered freely and without any external prompting. Indeed, it was sometimes explained that caring for service users outside of the hours of paid care went against company policy:

[Provider] were very clear about professional boundaries, and absolutely right, but I have to say that, it's actually really, really hard. Because, you 
know, today, I just made crème caramel at home before I came out... and I'll take them over with me. And, all the carers do it. They always bring cakes over and little things, when we go on holiday, there's a little something that we'll bring back. Strictly speaking, it's a no-no.

Nevertheless, in spite of the employer's explicit advice about protecting boundaries, tacit organisational expectations of good homecare may have influenced homecare workers' behaviour in more subtle ways. One manager who was involved in staff training explained:

As I say during induction, 'We leave home at home'. We all have personal relationship, financial, children, whatever it is, problems, but when you are there, you are there for that person. So, it's somebody who has got a positive outlook, and energy...And they're also willing to do some extra work. And by extra work, I mean, find out more about, not just the individual, but about some of the things they can bring to the person.

(HM04)

The expectation in this quotation of always being positive and willing to 'do some extra work' underscores how emotional investment is seen by the employer as an indicator of superior care. It appears that homecare workers may thus be incentivised to apply their emotions, even beyond the standard requirements of the job description, in order to be acknowledged as good carers. It could be argued that, in requiring homecare workers to present a positive front, the employer encouraged homecare workers to maintain a professional distance between their private selves and their work. However, this may 
have involved some cost to the individual in terms of preserving authenticity through having to suppress their feelings in order to effectively do the emotional work of caring.

Maintaining a balance between investing emotionally in their work and protecting themselves from potential consequences sometimes required careful calibration. For example, one homecare worker described how she weighed the personal costs of extending her visit to a client against the likelihood of raising expectations and incurring longer term costs:

I spent the evening with her and we watched Strictly Come Dancing together, which we both enjoy and you just think, it doesn't really matter, I'd probably do the same thing at my own house. And fortunately, she doesn't remember it, so it doesn't become a habit, because, of course, that's the danger, that if you go beyond once or twice, it becomes expected.

(HW06)

In this example, the client's expectations of, and responses to, the homecare worker's actions were considered prior to her offer of unpaid companionship to the client. The emotional work of accompaniment is presented as the outcome of a rational process of cost-benefit analysis, suggesting that there may be circumstances in which an intrinsic orientation to care may operate alongside an assessment of the likely impact of care on the recipient and on the homecare worker themselves. The extent to which homecare workers take into account the perspectives of clients in determining when, or when not, to go the extra mile suggests a performative element to their voluntary labour, in that it is calculated to achieve a certain level of return on the investment. 
Homecare workers' interactions with other family members also influenced the decision to undertake additional work. For example, one homecare worker reported receiving positive feedback from a family member after using her own time to research a service user's life story:

His son said to me, 'You know, it's fantastic because my dad is really proud about his achievements and when people come and talk to him, they don't really know very much about him'.

(HCW15)

Through putting in extra time, this individual was able to enhance her reputation for being a good carer and to bolster the company's status as an outstanding homecare provider. The importance homecare workers placed on reputation also underlined the performative nature of the work. Homecare workers expressed concern with how their care was assessed by service users, relatives, other homecare workers and service managers. Being seen to be a good carer was a motivating factor for undertaking certain tasks, even when to do so went above and beyond their role.

Sometimes, the benefits homecare workers accrued from going the extra mile in terms of enhanced reputation or job satisfaction did not appear to outweigh the material costs:

I always brought her plants and cakes, and I took her out, we did nice things. You know, we had lunch together occasionally - [by] the time I paid for my lunch, [it] wasn't worth me going, because that was my hourly rate gone. (HCW02)

It appears, therefore, that going the extra mile was not always undertaken unconditionally without the expectation of recognition and reward, and there were limits to the extent 
homecare workers were prepared to go beyond their contractual duties. In this example, the worker acknowledges that her pay for the call was spent on the shared lunch on one occasion that 'wasn't worth me going', indicating that this marked the limit of her voluntary labour.

In summary, the performative mode of going the extra mile appeared to be motivated by a concern for enhancing the homecare worker's reputation as a good carer, Where it resulted in direct recognition and appreciation from service users, other homecare workers, relatives or their employer, this form of voluntary labour could also lead to increased job satisfaction. If this was not forthcoming, the opposite could occur.

\section{Pragmatic voluntary labour}

Sometimes, going the extra mile appeared to be the result of a more pragmatic appraisal by homecare workers in that it was simply necessary to get a good job done:

I like to leave [the house] clean, tidy, know that they're all settled with whatever they need, and if that eats into an extra five or ten minutes to me, with my time, I think, well, at least I'm not worrying about what I've left.

(HCW04)

My time management on these visits is poor as I feel I want to clean as much as possible for them and chat. However, today I did improve and only spent fifteen minutes too long.

The homecare workers in our study were working for an employer who specified a minimum of one hour for each visit. Even so, it was sometimes difficult to complete the necessary practical tasks and find time for the emotional work of offering empathy, social 
support and companionship. Staying beyond their allocated time was one way in which homecare workers could ease some of the pressure arising from the various demands of the job. Homecare workers sometimes reflected a sense of injustice at the need to work beyond their allocated hours:

...if I am late, I always give ten minutes, mainly of my own time...Even though I should have been there for twelve, and I am at work. It's not as if it's my fault I'm late, it's because I'm at the other lady.

(HCW02)

The domino effect on the day's schedule of staying late with one service user and the unpredictability of travel time between service users sometimes placed homecare workers under pressure. Some homecare workers tried to manage their workload and maintain a high standard of care by absorbing any additional time into their free time, effectively subsidising care costs at their own expense.

In these examples, homecare workers' actions in going the extra mile appeared to draw on their moral commitment to ensuring the safety and well-being of service users. There was no explicit requirement to input unpaid time and incur direct costs, and the employer may not have been aware of the extent of this practice amongst the workforce.

The pragmatic mode of going the extra mile appeared to be triggered by the unpredictable demands of the job and the logistical problems of scheduling, which meant that homecare workers felt it necessary to donate their time in order to achieve the requirement of providing good care. It is possible that the affective dimension of homecare, which was an unspecified yet unavoidable aspect of their work, led to the delay in homecare workers 
completing practical tasks. Pragmatic voluntary labour could therefore be seen as an implicit expectation of the informal labour process as defined by Bolton and Wibberley (2014), through which a sense of moral obligation for the care of vulnerable older people living at home was met.

\section{DISCUSSION}

Our study of the on-the-job experiences of homecare workers in delivering care to older people with dementia points to the complex relationships between personal gratification and esteem, social benefit and commercial gain in the homecare work sector. Homecare workers' motivations for going the extra mile appear to differ in identifiable ways. At times, homecare workers appeared strongly motivated by an affective disposition to provide care for others. However, other factors were salient to the performance of voluntary labour, including a felt need to demonstrate good care, and a desire to get the job done. We found that voluntary labour above and beyond the job role could lead to an increase in self-esteem and job satisfaction. However, it could also incur costs in the form of money, material goods, well-being and occasionally, goodwill.

Achieving the goal of good homecare presents particular challenges for homecare workers when older people have complex needs. Routine tasks may take longer to complete when a service user has dementia, making it more likely that the work will extend beyond the allocated time. The presence of dementia may also affect attempts at relationship building. While some homecare workers did appear to form strong attachments with clients; the reciprocity, responsiveness and mutuality that characterise positive relationships were sometimes absent, especially when service users had advanced dementia. In circumstances where it can be difficult to achieve a positive sense 
of emotional engagement, our research suggests that job satisfaction may also be enhanced by attending to the effective performance of a good care relationship. The recognition and appreciation of their efforts by relatives or their employer could act as a reward and encourage the practice of going the extra mile as a means of sustaining a reputation as a good carer.

Sometimes it appeared that homecare workers went above and beyond the job role out of a sense of pride in the work itself, since care relationships were not always gratifying and there was often no-one to witness their additional effort. On these occasions, going the extra mile can be seen as a manifestation of the 'caring self' as described by Stacey (2011) and suggests that the sense of being engaged in vocational work which stems from an internalised predisposition to care was adequate compensation for any voluntary labour undertaken.

However, the wider social and economic conditions under which homecare is delivered also informed our understanding of homecare workers' motivations in going the extra mile. In a sector in which the labour required to provide homecare is systematically under-resourced (Humphries et al., 2016), going the extra mile was sometimes the result of a pragmatic decision, in that it was simply necessary to get a 'good' job done. In these circumstances, going the extra mile could be interpreted as more or less a product of a coercive labour practice which draws on the emotional commitment of homecare workers to elicit unpaid work.

There is a risk that the homecare workforce could be subjected to exploitation as pressures on the social care market continue to increase. The Association of Directors of Adult Social Services (ADASS) estimate the funding gap for adult social care in England 
will reach $£ 4.3$ billion by 2020 (ADASS, 2015). Although for some homecare workers, the intrinsic rewards derived from their work appear to outweigh any material benefits, further research is needed to explain their general lack of influence over working conditions, which goes beyond the remit of the present study.

A weakness of the study is that participants were self-selecting; some homecare workers may have been actively encouraged by their employers to take part, whilst those who did not conform to employer expectations may have been screened out. Homecare workers' diaries in particular showed some signs of presentation-management by the writers, in which their narratives were shaped to give a positive account of the self and their commitment to the job (Travers et al., 2018).

Overall, homecare workers could be seen to operate in a space between 'the caring self' and the 'professional' worker. Our respondents sometimes described experiencing a genuine connection with an older person with dementia, but also gave accounts of the performance of closeness in which they drew on personal attributes and skills to simulate a positive relationship and to enhance the delivery of care. Our findings imply that homecare workers are going the extra mile in furthering their attempts to be, and to be seen as, good at the job.

\section{CONCLUSION}

Our study indicated that homecare workers are using their material, social and emotional resources to deliver good homecare to older people with dementia. It was evident from homecare workers' accounts that the relational work of good homecare relies on a set of accomplished skills as well as intrinsic abilities, but more research is needed to fully 
understand how these relate to homecare workers' motivations and perceived rewards. However, if a willingness to go the extra mile is to be seen as a criterion for superior care, there is a need to differentiate between labour (emotional and practical) that is truly voluntary and that which results from a systemic under-resourcing of the homecare sector. Whilst the former appears to produce rewards for homecare workers, the latter has the potential to represent an infringement of homecare workers' legal and moral rights. The extent to which this is economically viable and morally sustainable in the long-term are important questions for those involved in the commissioning, organisation and delivery of homecare services to consider. 


\section{REFERENCES}

Alzheimer's Society (2014). Dementia UK: Update. Retrieved from http://www.cfas.ac.uk/files/2015/07/P326_AS_Dementia_Report_WEB2.pdf

Association of Directors of Adult Social Services (2015) Distinctive, Valued, Personal:

Why Social Care Matters. Retrieved from https://www.adass.org.uk/distinctivevalued-personal-why-social-care-matters

Bailey, S., Scales, K., Lloyd, J., Schneider, J., \& Jones, R. (2015). The emotional labour of health-care assistants in inpatient dementia care. Ageing and Society, 35(2), 246-269.

Banijamali, S., Jacoby, D., \& Hagopian, A. (2014). Characteristics of Home Care Workers Who Leave Their Jobs: A Cross-Sectional Study of Job Satisfaction and Turnover in Washington State. Home Health Care Services Quarterly, 33(3), 137158.

Bolton, S. C., \& Wibberley, G. (2014). Domiciliary Care: The Formal and Informal Labour Process. Sociology, 48(4), 682-697.

Briar, C., Liddell, E., \& Tolich, M. (2014). Still working for love? Recognising skills and responsibilities of home-based care workers. Quality in Ageing and Older Adults, 15(3), 123-135.

Bubb, S. (2014) Winterbourne View - Time for Change: Transforming the commissioning of services for people with learning disabilities and/or autism. Retrieved from https://www.england.nhs.uk/wpcontent/uploads/2014/11/transforming-commissioning-services.pdf 
Carter, D. (2016). Fix Dementia Care: Homecare. Alzheimer's Society. Retrieved from https://www.alzheimers.org.uk/homepage/195/fix_dementia_homecare

Charmaz, K. (2006). Constructing Grounded Theory: A Practical Guide Through Qualitative Analysis. London: Sage.

Cranford, C. J., \& Miller, D. (2013). Emotion management from the client's perspective: the case of personal home care. Work, employment and society, 27(5), 785-801.

de São José, J., Barros, R., Samitca, S., \& Teixeira, A. (2016). Older persons’ experiences and perspectives of receiving social care: a systematic review of the qualitative literature. Health \& Social Care in the Community, 24(1), 1-11.

Fleming, G., \& Taylor, B. J. (2007). Battle on the home care front: perceptions of home care workers of factors influencing staff retention in Northern Ireland. Health \& Social Care in the Community, 15(1), 67-76.

Francis, R. (2013). Report of the Mid Staffordshire NHS Foundation Trust Public Inquiry. London, Stationary Office.

Hochschild, A. R. (1983). The Managed Heart: Commercialisation of Human Feeling. Berkeley: University of California Press.

Holmes, J. (2016) An Overview of the Domiciliary Care Market in the United Kingdom. Retrieved from https://www.ukhca.co.uk/pdfs/DomiciliaryCareMarketOverview2015.pdf

Humphries, R., Thorlby, R., Holder, H., Hall, P. and Charles, A. (2016). Social care for older people: Home truths. London, The King's Fund. 
Jang, Y., Lee, A. A., Zadrozny, M., Bae, S.-H., Kim, M. T., and Marti, N. C. (2015). Determinants of Job Satisfaction and Turnover Intent in Home Health Workers. Journal of Applied Gerontology, 36(1), 56-70.

Johnson, E. K. (2015). The business of care: the moral labour of care workers. Sociology of Health \& Illness, 37(1), 112-126.

Manthorpe, J., Harris, J., Samsi, K., \& Moriarty, J. (2017). Doing, Being and Becoming a Valued Care Worker: User and Family Carer Views. Ethics and Social Welfare, 11(1) 79-91.

Palmer, E., \& Eveline, J. (2012). Sustaining Low Pay in Aged Care Work. Gender, Work \& Organization, 19(3), 254-275.

Sims-Gould, J., Byrne, K., Craven, C., Martin-Matthews, A., \& Keefe, J. (2010). Why I Became a Home Support Worker: Recruitment in the Home Health Sector. Home Health Care Services Quarterly, 29(4), 171-194.

Skills for Care (2016). Study into the impact of a values based approach to recruitment and retention. Retrieved from http://www.skillsforcare.org.uk/Documents/NMDS-SC-andintelligence/Research-evidence/Values-based-recruitment-Final-evaluationreport.pdf

Stacey, C. L. (2005). Finding dignity in dirty work: the constraints and rewards of lowwage home care labour. Sociology of Health \& Illness, 27(6), 831-854.

Stacey, C. L. (2011). The Caring Self: The Work Experiences of Home Care Aides. Ithaca, NY: Cornell University Press. 
Thompson, P., \& Smith, C. (2009). Labour Power and Labour Process: Contesting the Marginality of the Sociology of Work. Sociology, 43(5), 913-930.

Travers, C., Schneider, J., Scales, K. Perry-Young, L. Wilkinson, S., \& Pollock, K., (2018). Close encounters of the caring kind: Using a reflective diary methodology to investigate the experiences of paid homecare workers caring for people with dementia. BPS Division of Occupational and Organisational Psychology Conference Abstracts 197-198, January 2018.

Ward, J. \& McMurray, R. (2016). The Dark Side of Emotional Labour. Abingdon: Routledge. 